\title{
CD 95-independent mechanisms of IL-2 deprivation- induced apoptosis in activated human lymphocytes
}

\author{
T Hieronymus ${ }^{1}$, N Blank ${ }^{1}$, M Gruenke ${ }^{1}$, S Winkler ${ }^{1}$, J-P Haas ${ }^{2}$, \\ JR Kalden ${ }^{1}$ and H-M Lorenz ${ }^{\star, 1}$ \\ ${ }^{1}$ Department of Medicine III, Institute for Clinical Immunology and \\ Rheumatology, University of Erlangen-Nuremberg, 91054 Erlangen, Germany \\ 2 Children's Hospital, University of Erlangen-Nuremberg, 91054 Erlangen, \\ Germany \\ * Corresponding author: Dr H-M Lorenz, University of Erlangen-Nuremberg, \\ Department of Medicine III, Institute for Clinical Immunology/Rheumatology, \\ Krankenhausstr. 12, 91054 Erlangen, Germany, Tel: ++49-9131-85-9107; \\ Fax: ++49-9131-85-4770; \\ E-mail: Hannes.Lorenz@med3.imed.uni-erlangen.de
}

Received 20.4.99; revised 25.1.00; accepted 18.2.00

Edited by A Strasser

\begin{abstract}
Growth factor deprivation-induced apoptosis plays an important role in several cellular systems. However, knowledge of the molecular mechanisms involved are restricted to a few murine models or tumor cell lines. Therefore, we aimed studying signaling pathways leading to apoptosis in activated human peripheral T cells after IL-2 withdrawal. Lymphoblasts from patients with CD 95 (Fas/APO-1)-deficiency revealed that functional CD95 was not required to induce apoptosis after IL2 withdrawal. Moreover, apoptosis induction in response to various cytotoxic stimuli was found to be mediated in the absence of functional CD95 but was affirmatorily influenced by IL-2 signaling. Immunoblots showed no downregulation of $\mathrm{Bcl}-2$ or Bcl- $\mathrm{x}_{\mathrm{L}}$ and no upregulation of $\mathrm{Bax}$, whereas decreased mitochondrial membrane potential was readily measurable $24 \mathrm{~h}$ after cytokine deprivation. Tetrapeptide inhibitors showed limited efficacy in preventing apoptosis whereas the caspase inhibitor ZVAD-FMK potently blocked induction of apoptosis. Cleavage of different fluorogenic substrates revealed multiple caspase enzyme activities in lymphoblasts, which were not negatively affected by the fas mutation. Starting at $8 \mathrm{~h}$ after IL-2 withdrawal, upregulation of active caspase- 3 but not of caspase- 8 could be detected. Taken together, our data argue for molecular mechanisms of cytokine deprivation-induced apoptosis in activated human lymphocytes independent of CD95. Cell Death and Differentiation (2000) 7, 538-547.
\end{abstract}

Keywords: IL-2; CD95/Fas/Apo-1; lymphokine withdrawal; Canale-Smith-Syndrome; caspases

Abbreviations: AICD, activation induced cell death; PARP, poly(ADP-ribose) polymerase; $\mathrm{PI}$, propidium iodide; ZVAD-FMK, benzyloxycarbonyl-Val-Ala-Asp(OMe)-fluoromethyl ketone

\section{Introduction}

Apoptosis, a genetically programmed mechanism for elimination of cells in response to various stimuli, is a fundamental process in multicellular organisms for normal development of different tissues including the immune system in higher vertebrates and man. ${ }^{1,2}$ During an immune response, cells of the appropriate antigenic specificity must undergo clonal expansion to yield a protective response, and cells participating in inflammatory immune response need to have the capacity to survive at sites of inflammation. However, upon completion of a successful response, the majority of activated cells must be eliminated in order to maintain the homeostasis of the organism. .,4 $^{3,4}$

The Fas(APO-1/ CD95)/Fas ligand (FasL) system is thought to play a central role in activation-induced cell death (AICD), and the Fas-dependent signaling cascade was extensively studied in this cellular model. Fas is highly expressed on activated mature $\mathrm{T}$ cells, ${ }^{3,5}$ and stimulation with FasL or agonistic antibodies leads to the autocatalytic activation of caspase-8 (FLICE/MACH). ${ }^{6}$ This member of the ICE-protease family initiates a proteolytic cascade of intracellular signaling events that cause the activation of other ICE-related proteases like caspase-3 (CPP32/ apopain/Yama) and subsequent proteolysis of vital substrates (e.g. lamin, actin, U1snRNP and poly(ADP-ribose) polymerase (PARP)) which finally leads to the death of the cell (reviewed in ${ }^{7,8}$ ).

Mice bearing a mutation in the Ipr or gld gene loci which encodes for murine Fas and FasL, respectively, develop a lymphoproliferative disease associated with an SLE-like autoimmune disorder. ${ }^{9}$ The Fas/FasL system was also extensively analyzed in human lupus. However, patients with SLE do not appear to have a defect in Fas or FasL expression or function. ${ }^{10,11}$ On the other hand, different transgenic murine models on the Ipr/lpr background provided evidence for Fas independent mechanisms leading to apoptosis in activated T cells. ${ }^{12-15}$ However, this has not been shown in a model system using human cells.

IL-2 was shown to play a critical role in AICD in models employing $T$ cells undergoing apoptosis after $T$ cell receptor stimulation. ${ }^{16,17}$ Fournel et al. ${ }^{18}$ reported that human $T$ cells require IL-2 to acquire susceptibility to Fas-mediated apoptosis. This confirms similar observations in mice deficient for IL-2 or IL-2R in which impaired apoptosis induction through Fas was found. ${ }^{19-21}$ On the other hand, IL-2 is known as a pluripotent pro-inflammatory cytokine that serves as an important survival factor preventing apoptosis in several cellular systems ${ }^{22-24}$ including activated $\mathrm{T}$ cells. ${ }^{25,26}$ The complexity in the regulation of apoptosis, with the same growth factor promoting both, prevention or induction of programmed cell death dependent on the cellular activation status, lead to the theoretical 
concept of so called propriocidal regulation of apoptosis as proposed by Lenardo et al. According to this theory, IL-2 provides feedback susceptibility to 'active' (Fas- or TNFdependent) and 'passive' (survival factor withdrawal) apoptosis. $^{27}$ Therefore, we aimed studying apoptosis induction in matured human peripheral lymphocytes under conditions of growth factor deprivation after activation with PHA and IL-2. We raised the question whether Fas, members of the Bcl-2 family and caspases are involved in the induction of apoptosis in our model system. Our data do not only confirm characteristics in the regulation of apoptosis in T cells which have been previously elucidated in different transgenic mouse strains or murine tumor $\mathrm{T}$ cell lines, but provides further insights in the mechanisms leading to apoptotic cell death in activated human $T$ lymphocytes after cytokine deprivation.

\section{Results}

\section{PHA blasts are susceptible to Fas-mediated and IL-2 withdrawal-induced apoptosis}

We and others have recently shown that PHA stimulation of PBMC leads to upregulated surface expression of Fas. ${ }^{5,28} \mathrm{We}$ did not observe quantitative changes in Fas surface expression thereafter, including the period before the addition of exogenous IL-2 at day 6 or after growth factor withdrawal. ${ }^{28}$ These cells also show upregulated Fas-ligand expression as assessed by immunoblotting (unpublished observation). It is proposed that IL-2 is not involved in the regulation of Fas or FasL expression but is required to render human $\mathrm{T}$ cells susceptible to Fas-mediated apoptosis. Therefore, in a first set of experiments we investigated, whether in our cellular model the PHA-activated lymphoblasts (PHA blasts) underwent apoptosis through Fas engagement under different culture conditions. The IL-2-deprived cells were incubated in the presence or absence of an apoptosis-

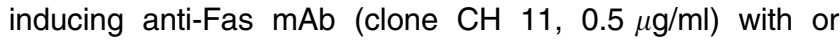
without IL-2 substitution as indicated in Table 1. PHA blasts readily underwent apoptosis after complete IL-2 withdrawal

Table 1 Specific apoptosis induction through anti-Fas $\mathrm{mAb}$ in the presence or absence of IL-2

\begin{tabular}{lcrcc}
\hline & Anti-Fas & \multicolumn{3}{c}{ Apoptosis (\%) } \\
& mAb & $\mathbf{2 4 ~ h}$ & $\mathbf{4 8 ~ h}$ & $\mathbf{7 2 ~ h}$ \\
\hline Medium & 0 & $16.3 \pm 5.5$ & $37.0 \pm 3.3$ & $56.6 \pm 1.8$ \\
& + & $22.3 \pm 6.9$ & $46.0 \pm 4.2^{\star}$ & $54.9 \pm 3.6$ \\
+IL-2 $1 \mathrm{U} / \mathrm{ml}$ & 0 & $7.3 \pm 1.9$ & $12.4 \pm 1.1$ & $19.6 \pm 2.1$ \\
& + & $10.7 \pm 3.7$ & $29.4 \pm 6.1^{\star *}$ & $31.3 \pm 2.6^{\star \star *}$ \\
+IL-2 $10 \mathrm{U} / \mathrm{ml}$ & 0 & $5.7 \pm 1.7$ & $9.0 \pm 2.6$ & $11.0 \pm 2.2$ \\
& + & $10.3 \pm 3.3$ & $16.3 \pm 5.5$ & $23.4 \pm 4.0^{\star *}$ \\
\hline
\end{tabular}

PHA blasts were generated as described in Materials and Methods. After extensive washing a total of $4 \times 10^{5}$ cells per well were incubated as specified. Anti-Fas mAb (clone $\mathrm{CH} 11$ ) was used in a final concentration of $0.5 \mu \mathrm{g} / \mathrm{ml}$ to induce specific Fas-mediated apoptosis. At the indicated time, the rate of apoptosis was determined by PI-staining. Asterisks indicate significant differences between specific Fas-induced rate of apoptosis versus control without Fas mAb $\left({ }^{\star} P<0.05 ;{ }^{* \star} P<0.01 ;{ }^{* \star} P<0.001\right.$, as assessed by Student's $t$ test). Data shown are mean values \pm S.E.M. from seven independent experiments (medium), and additional stimulation with anti-Fas mAb could further increase the number of apoptotic cells. However, the difference between deprivation-induced and Fas-mediated apoptosis diminished when apoptosis was measured after prolonged incubation (72 h). IL-2 at optimal concentrations could effectively prevent induction of apoptosis in activated lymphoblasts after growth factor withdrawal in a dosedependent fashion. Although the anti-Fas mAb was able to increase the rate of apoptosis in the presence of IL-2, it did not attain the levels of apoptosis in complete IL-2 deprived cells. Based on these data we hypothesize that the intracellular IL-2 and Fas signaling pathways can interfere with each other in activated lymphoblasts.

\section{Functional Fas expression is not required to induce apoptosis in activated lymphocytes after growth factor deprivation}

In order to test this hypothesis we next investigated whether Fas/FasL interaction is required for induction of apoptosis after IL-2 deprivation. To this end we used an antagonistic Fas mAb (clone SM1/23) or a mAb against FasL (clone NOK-1) to block Fas/FasL interaction and therefore abrogate Fasmediated induction of apoptosis. Both antibodies were first tested in concentrations up to $10 \mu \mathrm{g} / \mathrm{ml}$ in Jurkat cells treated with the inducing anti-Fas mAb CH $11(1 \mu \mathrm{g} / \mathrm{ml})$ or sFasL $(100 \mathrm{ng} / \mathrm{ml})$. Effective inhibition of Fas-mediated apoptosis induction was already observed using $5 \mu \mathrm{g} / \mathrm{ml}$ of the blocking antibodies (data not shown). Next we investigated whether these antagonistic antibodies could effectively block specific Fas-mediated apoptosis in our cellular model. In parallel to our experiments shown in Table 1, cells were deprived of growth factor and cultured with low amount of IL-2 (1 U/ml) to obviate deprivation-induced apoptosis and allow specific Fasmediated induction using anti-Fas $\mathrm{mAb} \mathrm{CH} 11(1 \mu \mathrm{g} / \mathrm{ml}$,) or sFasL $(100 \mathrm{ng} / \mathrm{ml})$. As shown in Figure $1 \mathrm{~A}$ the antagonistic antibody SM1/23 was able to block Fas-mediated apoptosis. The sFasL binding antibody NOK1 was also able to abrogate Fas/FasL interaction and diminished sFasL-induced apoptosis. However, it failed to inhibit the $\mathrm{CH} 11$ antibody-mediated induction of apoptosis (Figure 1A). In contrast, neither SM1/23 nor NOK1 were able to reduce the rate of apoptosis which was induced due to complete deprivation of growth factor in our cellular model (Figure 1B).

To further support our evidence for a Fas-independent induction of apoptosis after cytokine withdrawal in activated human lymphoblasts, we compared PHA blasts generated from two individuals with a single fas gene mutation with PHA blasts derived from healthy donors (NHD). The fas gene mutations in these patients lead to an amino acid exchange at position 268 from glutamine to prolin but do not affect normal surface expression of CD95. ${ }^{29}$ After extensive washing PHA blasts were incubated with $1 \mathrm{U} / \mathrm{ml}$ IL-2 in the presence or absence of $1 \mu \mathrm{g} / \mathrm{ml}$ of the apoptosis-inducing anti-Fas $\mathrm{mAb}$ or left unstimulated as indicated (Figure 2A). Cytokine deprivation- and Fasmediated induction of apoptosis was measured after $24 \mathrm{~h}$. The data shown in Figure 2A indicate that the fas mutation abrogates the ability of the anti-Fas $m A b$ to induce apoptosis in PHA blasts from these individuals, whereas 
A

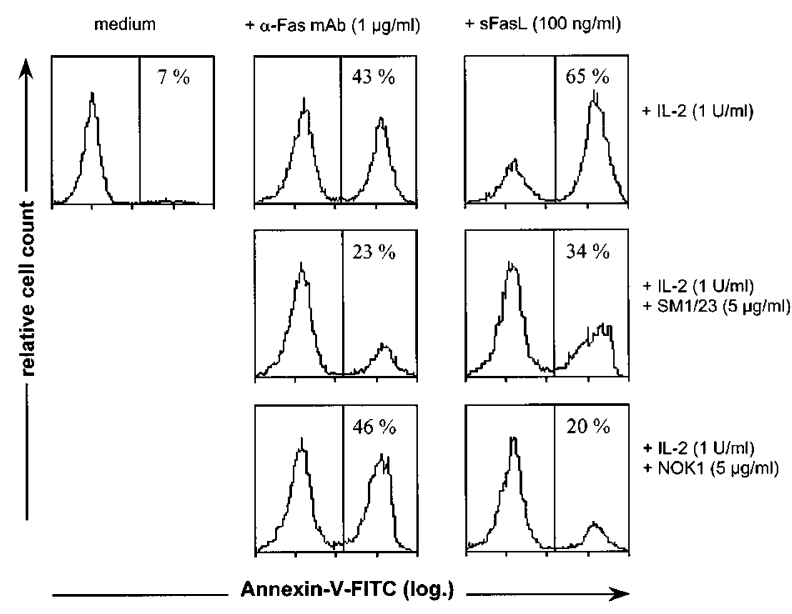

B

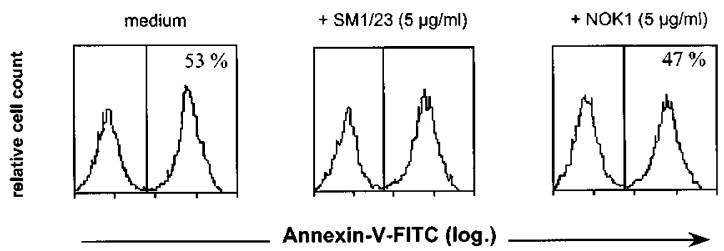

Figure 1 Fluorescence-histograms of Annexin-V-stained PHA blasts after growth factor withdrawal. A total of $4 \times 10^{5}$ cells per sample were incubated with or without blocking antibodies in a 24-well plate as indicated and rates of apoptotic cells were determined after $24 \mathrm{~h}$ of incubation as described in Materials and Methods. The percentage of cells staining positive for Annexin$V$ is indicated in each histogram. (A) Specific induction of apoptosis through anti-Fas mAb or sFasL in the presence of IL-2 $(1 \mathrm{U} / \mathrm{ml})$. (B) Growth factor deprived PHA blasts without further stimulation. Results shown are representative from one out of four different experiments

in cells from NHD, Fas stimulation readily increased percentage of apoptotic cells. Similar results were seen using sFasL (data not shown). Importantly, however, unstimulated lymphoblasts from all individuals tested showed enhanced rates of apoptosis at $24 \mathrm{~h}$ without differences between patients and their matched controls (Figure 2A). Furthermore, prolonged incubation of these lymphoblasts in the presence or absence of IL-2 $(10 \mathrm{U} / \mathrm{ml})$ again did not indicate differences in the percentage of apoptotic cells (Figure 2B). Together, these data indicate that induction of apoptosis by growth factor deprivation in activated human lymphoblasts does not require expression of functional Fas.

Furthermore, we tested different cytotoxic stimuli, like etoposide, dexamethasone, $\gamma$-irradiation and UV-irradiation which were described to CD95-independently induce apoptosis in $I p r$ mice or a CD95-resistant cell line. ${ }^{15,30}$ Consistent with the findings in other cellular models these agents induced apoptosis in PHA-activated human lymphoblasts derived from the patients with the fas gene mutation comparable to PHA blasts from normal healthy donors (Figure 3). IL-2 again rescued a significant number of lymphoblasts from apoptosis in the presence of dexamethasone, or after $\gamma$-irradiation, UV-irradiation and - to a lesser extent - after treatment with etoposide (Figure 3). According to previous observations in mouse models we conclude that there are various ways to induce apoptosis in the absence of functional CD95. However, the proapoptotic mechanisms tested are still controlled by survival signals as mediated by IL-2.

\section{Cytokine withdrawal leads to mitochondrial changes without regulating expression of $\mathrm{Bcl}-2$, $\mathrm{Bcl}-\mathrm{x}_{\mathrm{L}}$ or Bax}

Based on the finding that cytokine withdrawal-induced apoptosis seems to be independent of CD95, we next aimed at studying the intracellular signaling events after cytokine deprivation leading to programmed cell death in human lymphoblasts. $\mathrm{Bcl}-2$ and $\mathrm{Bcl}-\mathrm{x}_{\mathrm{L}}$ were shown to be regulated by IL-2 and potently inhibit dexamethasone- or $\gamma$-irradiationinduced apoptosis as well as cytokine deprivation-induced apoptosis. ${ }^{15,31-35}$ It is suggested that both factors inhibit apoptosis on the level of mitochondrial function which is discussed to be one of the very early markers for the point-ofno-return. ${ }^{36}$ Since in previous studies a decline in the expression of $\mathrm{Bcl}-2$ or $\mathrm{Bcl}-\mathrm{x}_{\mathrm{L}}$ was thought to be responsible for onset of apoptosis, ${ }^{31,37}$ we wondered whether in our cellular model cytokine deprivation leads to the reduction of mitochondrial transmembrane potential $\left(\Delta \Psi_{\mathrm{m}}\right)$. As shown in Figure 4, growth factor withdrawal-induced apoptosis leads to a similar decrease in mitochondrial transmembrane potential as seen after Fas engagement. In parallel to the apoptosis inhibitory potential of IL-2 less Fas-mediated reduction of $\Delta \Psi_{\mathrm{m}}$ was observed in the presence of IL-2 (Figure 4).

Next, we investigated the expression of the mitochondrial function-regulating molecules $\mathrm{Bcl}-2$, Bcl- $\mathrm{x}_{\mathrm{L}}$ and $\mathrm{Bax}$. Cell lysates from freshly isolated $\mathrm{PBMC}$ or $\mathrm{PHA}$-activated human lymphoblasts prepared at different time points after cytokine withdrawal were subjected to immunoblotting. As shown in Figure 5 we found no differences in the expression levels of $\mathrm{Bcl}-2, \mathrm{Bcl}-\mathrm{x}_{\mathrm{L}}$ and $\mathrm{Bax}$ during the process of apoptosis-induction after IL-2 deprivation. However, PHA-activated lymphoblasts showed upregulated expression of $\mathrm{Bcl}-\mathrm{x}_{\mathrm{S}}$ compared to PBMC, with the expression level revealing no profound increase during the apoptotic process.

\section{Requirement for proteases of the caspase-family in IL-2 deprivation-induced apoptosis}

Several studies highlighted the importance of caspases as intracellular transmitters of the pro-apoptotic signaling cascade. They showed that CPP32-like and ICE-like proteases are required for committing cells to undergo apoptosis in response to various stimuli. ${ }^{38,39}$ To investigate the role of caspases for induction of apoptosis in PHA blasts deprived of growth factors, we first tested different ICE-like protease inhibitors with different substrate specificities. AcYVAD-CHO is a highly potent caspase-1 (ICE) inhibitor $\left(\mathrm{K}_{\mathrm{i}}=0.76 \mathrm{nM}\right)$ but a poor inhibitor of caspase-3 $\left(\mathrm{K}_{\mathrm{i}}=10 \mu \mathrm{M}\right)$, Ac-DEVD-CHO is an excellent inhibitor of caspase-3 
A
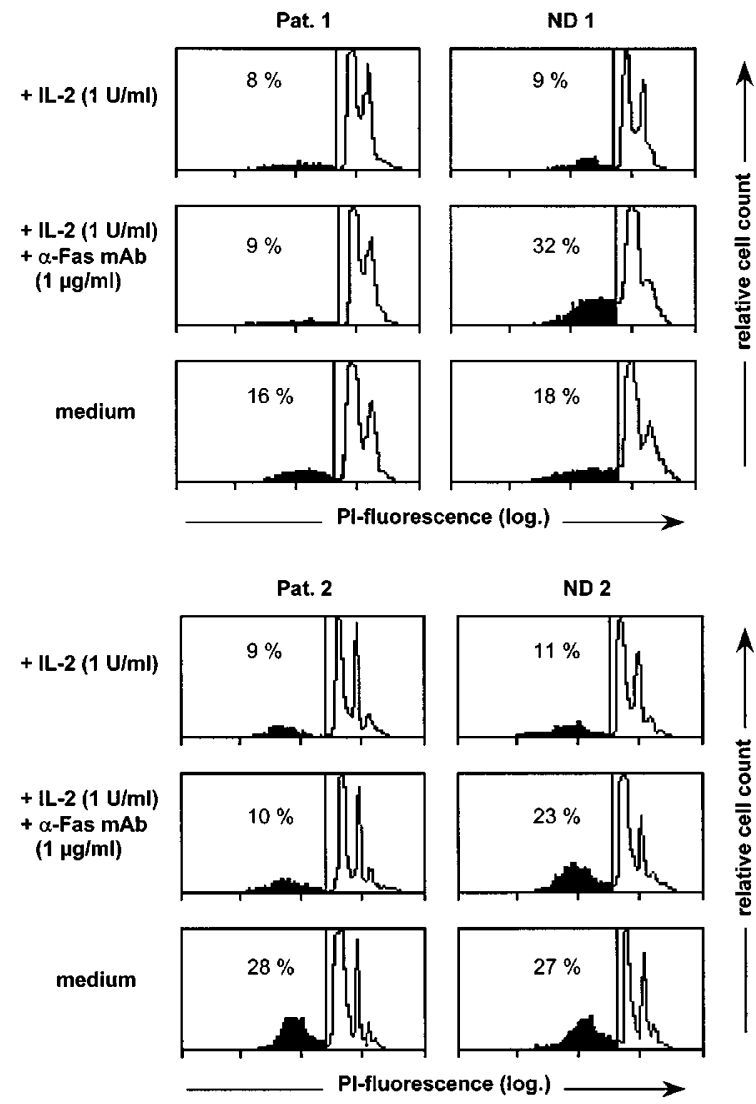

B

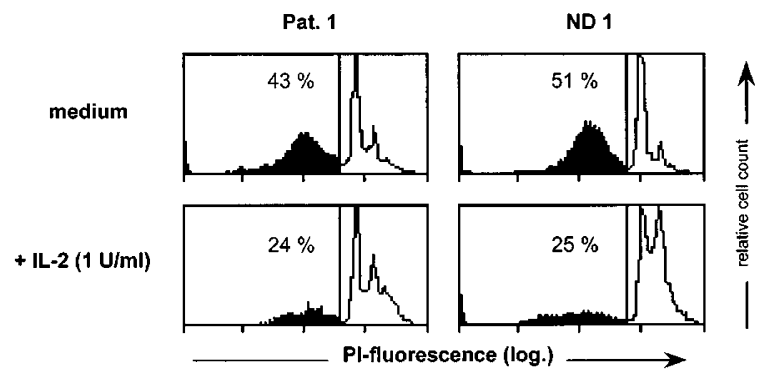

Pat. 2 ND 2

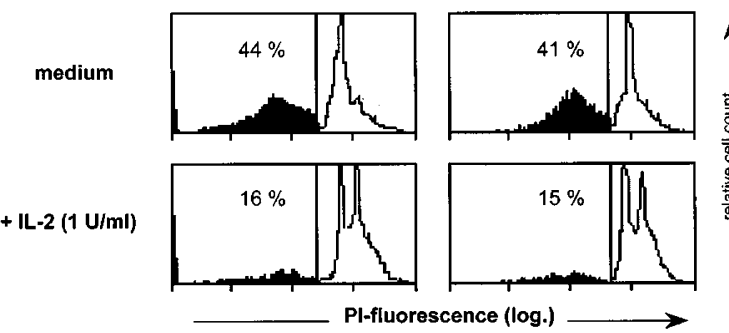

Figure 2 DNA content analysis of PHA blasts derived from two individuals with a fas gene mutation (Pat.) and their matched healthy controls (ND). PHA blasts were generated as described in Materials and Methods. After IL-2 expansion cells were extensively washed and incubated as indicated. (A) One $\mu \mathrm{g} / \mathrm{ml}$ of the anti-Fas $\mathrm{mAb}$ were used for apoptosis induction. PI staining was performed after $24 \mathrm{~h}$ of cytokine withdrawal. (B) PHA blasts were deprived of growth factor and incubated in the presence or absence IL-2 as indicated. PI
$\left(\mathrm{K}_{\mathrm{i}}=0.35 \mathrm{nM}\right)$ and to lesser extent of caspase- $1\left(\mathrm{~K}_{\mathrm{i}}=17 \mathrm{nM}\right)$. ZVAD-FMK is a potent, non-reversible inhibitor which was shown to inhibit the processing of several caspases and possibly inhibits a caspase close to the initiation site of the apoptotic cascade. ${ }^{7}$ We tested different concentrations of the inhibitors in our system to obtain optimal inhibition (data not shown). For the following experiments we used $200 \mu \mathrm{M}$ as the optimal concentration of each inhibitor. Both tetrapeptide inhibitors were less effective in preventing apoptosis induction, but still reduced the rate with statistical significance, whereas ZVAD-FMK was as effective as $10 \mathrm{U} / \mathrm{ml} \mathrm{IL-2}$ in decreasing apoptosis (Figure 6). From these results we suggested that several caspases are involved. To delineate the role of caspases involved in deprivation-induced apoptosis more clearly, we tested cell lysates from IL-2 deprived PHA blasts for caspase enzyme activity. To this end, we used fluorogenic substrates with different specificities for the known caspases and monitored the enzymatic catalyzed release of the fluorochrome in a spectrofluorometer. ${ }^{40,41}$ In cell lysates from ND we found the highest cleavage activity for the release of fluorochrome from the substrate DEVD-AFC which reveals a predominant caspase- 3 or -7 like activity. This activity could be blocked completely when the caspase specific inhibitor Ac-DEVD-CHO was added to the assay (data not shown). Caspase activity was also seen for cleavage of VDVAD-AMC (a substrate for caspase-2, but also cleaved by caspase-3 and -7), IETD-AMC (caspase- $6,-8$ and granzyme B) and VEID-AFC (caspase-6). In cell lysates from ND almost no release of fluorochrome from WEHDAMC, a substrate for caspase- $1,-4$ or -5 could be observed (Figure 7). We also tested cell lysates from one CSS-patient (bearing the fas gene mutation) to examine whether recruitment and activity of different caspases might be modified due to the Fas-deficiency. Comparable cleavage activities were found for DEVD-AFC and IETD-AMC. In contrast, in the cell lysate from the CSS-patient increased enzyme activities compared to the cell lysate from ND were found for cleavage of VEID-AFC and VDVAD-AMC. Interestingly, a perceptible release of fluorochrome from WEHD-AMC was also monitored (Figure 7).

In order to further specify caspases responsible for the observed cleavage activity, we analyzed the expression of caspase-8 (FLICE), caspase-3 (CPP32/apopain/Yama) and the expression of PARP as a known substrate of caspase-3. PHA blasts were deprived of growth factors and $1 \times 10^{7}$ cells were lysed at different time points after withdrawal as indicated in Figure 8A. FLICE was described to be predominantly expressed as two functionally active isoforms, caspase-8/a and caspase-8/b. Stimulation through CD95 lead to rapid recruitment and cleavage of both isoforms. ${ }^{6}$ In growth factor deprived PHA blasts without further stimulation we also found both isoforms expressed with unaltered expression quantities at any time after the cytokine withdrawal (Figure 8A). On the other hand, we could only detected upregulated expression of procaspase-3

staining was performed $72 \mathrm{~h}$ after cytokine withdrawal. The percentage of cells with subdiploid DNA content (in black) is indicated in each histogram 


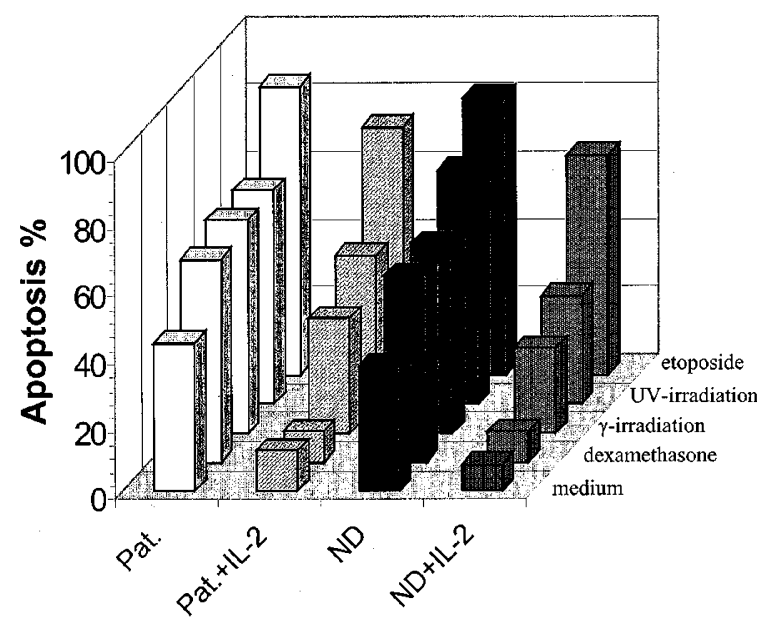

Figure 3 Comparison of different cytotoxic stimuli on apoptosis induction in PHA blasts from one CSS-patient with a fas gene mutation and a normal healthy donor (ND). A total of $4 \times 10^{5}$ cells per well were incubated as indicated and PI staining was performed after $72 \mathrm{~h}$

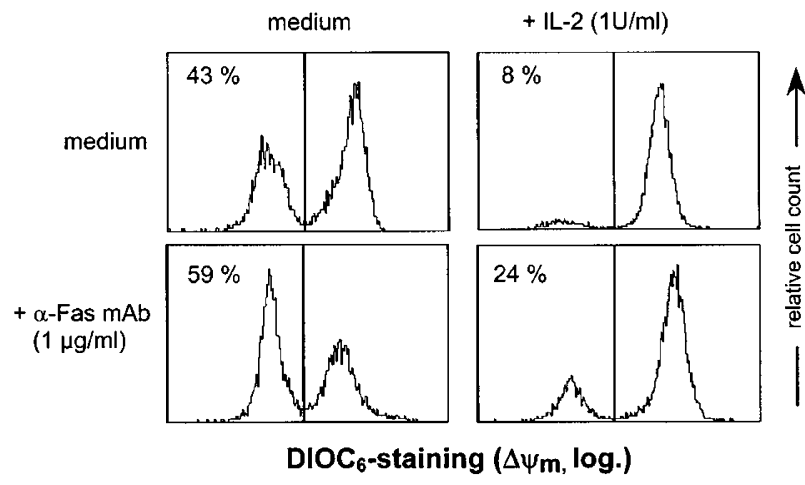

Figure 4 Fluorescence-histograms of $\mathrm{DiOC}_{6}$-staining for measuring mitochondrial transmembrane potential $\left(\Delta \Psi_{m}\right)$ in PHA blasts after cytokine withdrawal. Cells were incubated as indicated and $\Delta \Psi_{\mathrm{m}}$ was evaluated after staining with $\mathrm{DiOC}_{6}$ after $24 \mathrm{~h}$ as described in Materials and Methods. The percentage of cells with decreased $\Delta \Psi_{\mathrm{m}}$ is indicated in each histogram. The results shown are from one representative out of three separate experiments

$8 \mathrm{~h}$ after cytokine withdrawal accompanied by upregulated expression of the p17 subunit of the active complex. The large subunit of the activated complex was not further detectable after $32 \mathrm{~h}$ (Figure $8 \mathrm{~A}$ ). This upregulated expression of active caspase- 3 was paralleled by decreased expression of PARP (Figure 8A). As a positive control for procaspase-8 (FLICE) recruitment, we stimulated Jurkat cells or lymphoblasts with the agonistic anti-Fas mAb $\mathrm{CH} 11$. As shown in Figure 8B, stimulation through CD95 leads to rapid cleavage of procaspase-8/a and 8/b. again highlighting differences between growth factor withdrawalinduced and Fas-mediated apoptosis in human lymphoblasts on the molecular level.

\section{Discussion}

In the current study critical regulatory mechanisms for the induction of apoptosis after IL-2 withdrawal in activated

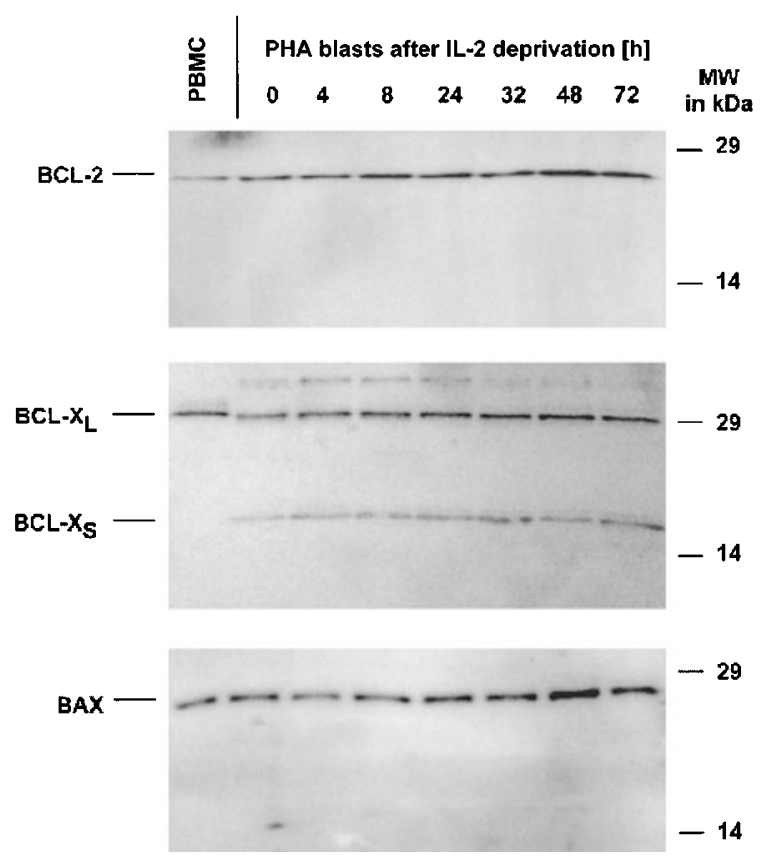

Figure 5 Protein levels of $\mathrm{BCl}-2, \mathrm{Bcl}-\mathrm{x}_{\mathrm{L}}, \mathrm{Bcl}-\mathrm{x}_{\mathrm{S}}$ and $\mathrm{Bax}$ in PHA blasts after cytokine deprivation and in freshly isolated PBMC. IL-2 expanded and extensively washed PHA blasts were lysed at the indicated time points after cytokine withdrawal. Immunoblots were performed as described in Materials and Methods. Results shown are representative for at least three independent experiments

human peripheral (non-lineage) lymphocytes were investigated. In the model applied, apoptosis induced by IL-2 withdrawal in vitro might resemble the in vivo situation when cytokine levels decrease after antigen clearance. Under those circumstances growth factor withdrawal-induced apoptosis should be an important mechanism to remove the large pool of antigen-specific effector cells in situations where antigen concentration and presentation alone cannot maintain the immune response and antigen-specific lymphocytes have been kept vital and expanding through lymphokine signaling. In this regard, IL-2 is thought to play an important role for a feedback mechanism of cell death control termed propriocidal regulation. ${ }^{27}$ It has been demonstrated, that IL-2 is exclusively essential in acquiring susceptibility to Fas-induced apoptosis. ${ }^{18,19}$ However, as new members of the TNF receptor family with intracellular death domains are identified, apoptosis in activated $\mathrm{T}$ lymphocytes might not depend on Fas-FasL interaction alone. Moreover, lymphokine withdrawal is presumed to represent a differentially regulated form of apoptosis induction. ${ }^{15,27,42}$

We could show that PHA blasts were susceptible to apoptosis induction through Fas engagement and IL-2 deprivation. Moreover, Fas-mediated apoptosis was delayed by supplementation of IL-2 in a dose-dependent fashion. This clearly shows an interdependence of pro- and anti-apoptotic signals in human lymphoblasts. Therefore, we raised the question whether in our system Fas/FasL interactions are directly involved in the induction of apoptosis after cytokine withdrawal. Two lines of evidence strongly argue against an involvement of Fas: first, 


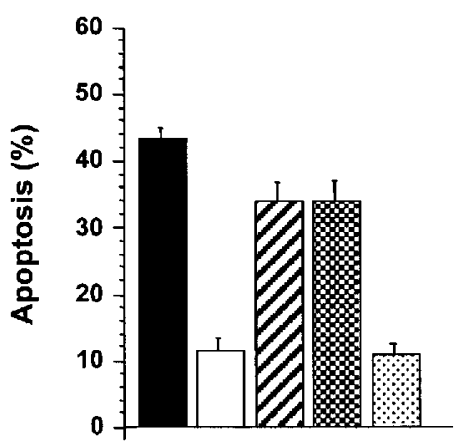

$\mathrm{IL}-2(10 \mathrm{U} / \mathrm{ml})-+-$ AC-DEVD-CHO $(200 \mu \mathrm{M})-\quad+-$ AC-YVAD-CHO $(200 \mu \mathrm{M})->-+$ ZVAD-FMK $(200 \mu \mathrm{M})$ - $-\quad-\quad+$

Figure 6 Inhibition of apoptosis through different peptide inhibitors of caspases. PHA blasts were extensively washed and incubated with the reagents as indicated for $72 \mathrm{~h}$. Inhibitor concentrations used in this experiment were $200 \mu \mathrm{M}$ for each. Differences to the medium control were significant $(P<0.01$, assessed by Dunnett's multiple comparison test). Data shown are mean values + S.E.M. from 12 different experiments

antagonistic antibodies against Fas or FasL failed to reduce the rate of apoptosis after cytokine withdrawal. Second, in PHA blasts generated from two individuals with fas gene mutation, Fas-mediated signals failed to induce apoptosis whereas normal levels of apoptosis were detected after IL-2 deprivation when compared to cells from normal donors. Similar observations of Fas-independent apoptosis induction after growth factor withdrawal in activated $T$ cells were described by Strasser et al. in a murine model on the $I p r / l p r$ background. ${ }^{15}$ Furthermore, blocking the function of FADD, which appears essential for apoptosis induced by several known death receptors revealed no effect on IL-2 deprivation-induced apoptosis. ${ }^{43,44}$ Together, these data provide strong evidence that cytokine deprivation-induced apoptosis does not require functional Fas expression or signaling in activated T cells.

Normal sensitivity to various cytotoxic stimuli in $\mathrm{Ipr} / \mathrm{lpr}$ mouse models ${ }^{12-15}$ or a CD95-resistant cell line ${ }^{30}$ were also described. Using dexamethasone, etoposide, UV- and $\gamma$-irradiation we could confirm Fas-independent induction of apoptotic cell death for these agents also in activated human peripheral (non-lineage) lymphocytes. Moreover, these mechanisms of apoptosis induction were still affected by anti-apoptotic signaling properties mediated by IL-2 signals.

A main question remains to be elucidated. How is loss of signaling through the IL-2 receptor linked to activation of the apoptotic cascade and especially to the recruitment of an initial caspase? From the IL-2 effects mediated through interaction with its specific receptor, activation of tyrosine kinases (including src- and Jak-kinases), serine-threonine kinases, lipid kinases (phosphatidylinositol 3-kinase) and activation of $\mathrm{p} 21^{\text {ras }}$ are more or less well defined. ${ }^{32}$ After the initial cytoplasmic events mediated by these molecules, transcription factors including Stat factors, c-myc, c-fos and c-jun are also activated, which probably control expression
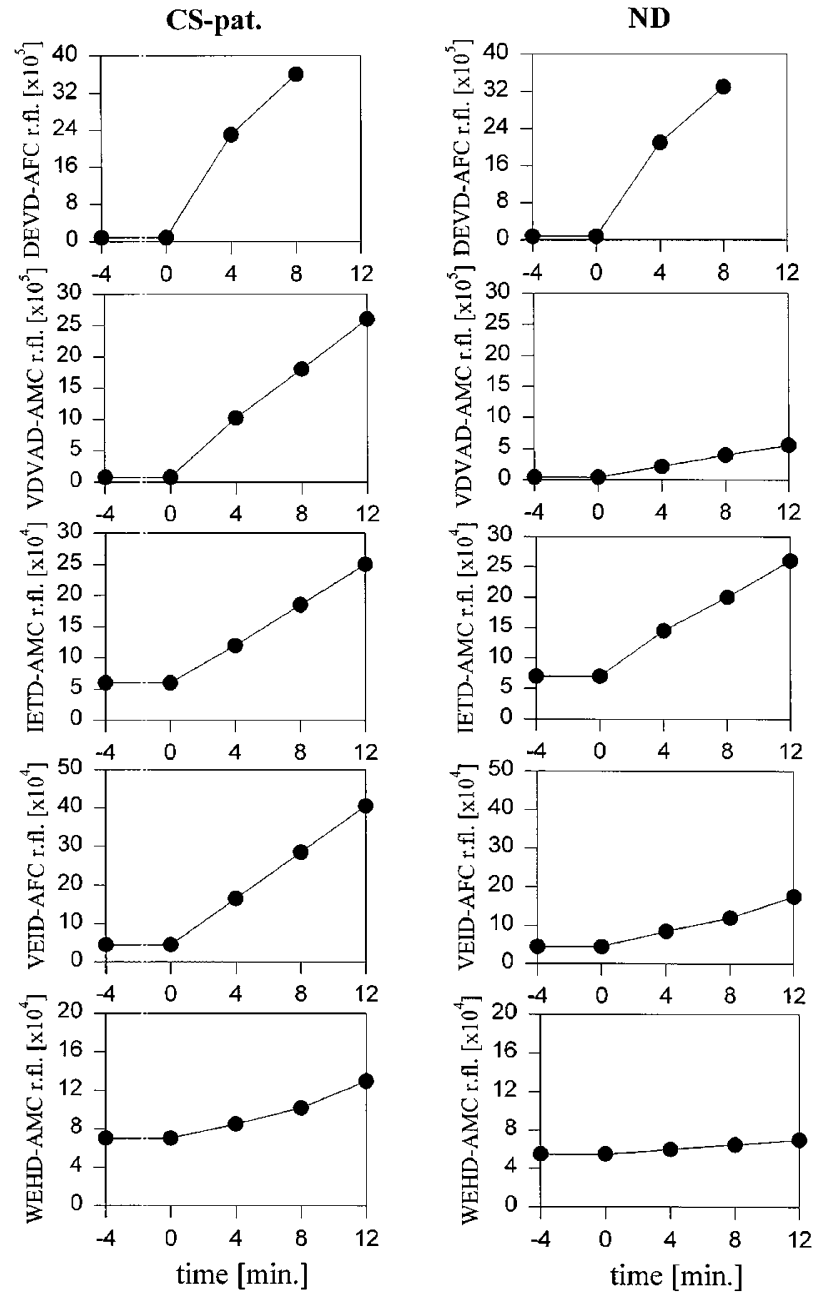

Figure 7 Spectrofluorometric analysis of caspase activities. Lysates from PHA Blasts deprived of growth factor were prepared as described in Material and Methods. The system was first equilibrated with assay buffer and the specific caspase substrate as indicated. At timepoint zero the cell lysate was added and cleavage of fluorochrome was continuously monitored. Release of AMC was measured using an excitation wavelength of $380 \mathrm{~nm}$ and an emission wavelength of $460 \mathrm{~nm}$. An excitation wavelength of $400 \mathrm{~nm}$ and an emission wavelength of $505 \mathrm{~nm}$ was used for monitoring the release of AFC. Data shown are representative from one of three different experiments using different cell lysate preparations

of genes involved in apoptosis regulation like $b c l-2, b c l-x_{L}$ and others. Bcl-2 and $\mathrm{Bcl}-\mathrm{x}_{\mathrm{L}}$ have been shown to inhibit (CD95-independent) forms of apoptosis induced by various stimuli, including growth factor withdrawal. ${ }^{15,34-36}$ How these factors mediate their anti-apoptotic effect is still unclear. It has been suggested that altered Bcl-2 activity leads to mitochondrial permeability transition (pore formation) and release of apoptogenic activators like cytochrome $c$ and apoptosis-inducing factor (AIF) with subsequent activation of caspases. ${ }^{45,46} \mathrm{~A}$ decline in $\mathrm{Bcl}-2$ or $\mathrm{BCl}-\mathrm{x}_{\mathrm{L}}$ protein expression or function has also been correlated to the induction of apoptosis after growth factor withdrawal. $^{31,37}$ On the protein level we could not detect changes in $\mathrm{Bcl}-2, \mathrm{Bcl}-\mathrm{x}_{\mathrm{L}}$ or Bax expression after IL-2 withdrawal (Figure 5). However, we found loss of mitochondrial 
A

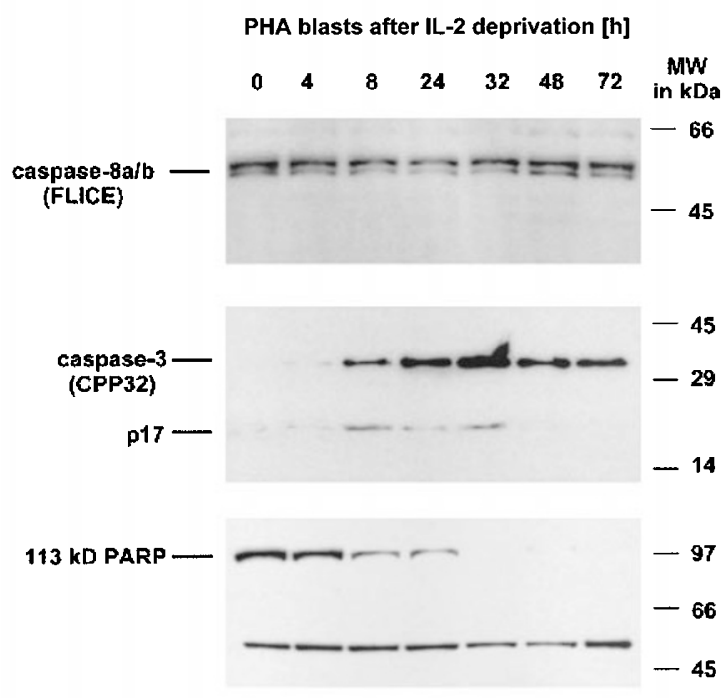

B

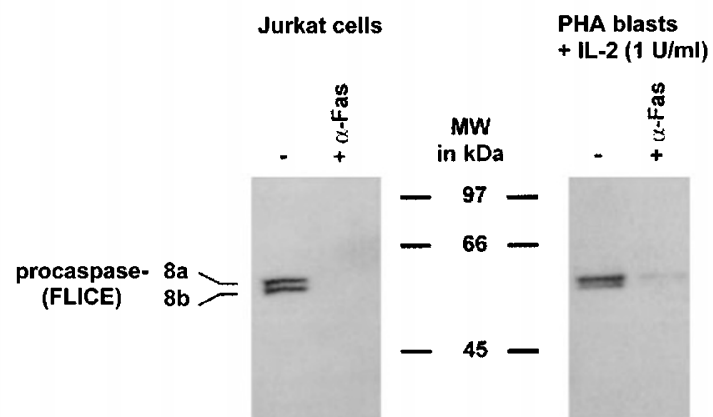

Figure 8 Time course of caspase-8 (FLICE), caspase-3 (CPP32), and PARP protein levels in PHA blasts after cytokine deprivation. IL-2 expanded and extensively washed PHA blasts were lysed at the indicated time points after cytokine withdrawal. Immunoblots were performed as described in Materials and Methods. Results shown are representative for at least three independent experiments

function to be one of the earliest apoptosis specific features besides caspase activation after IL-2 withdrawal (Figure 4). One possible mechanism was found in IL-3-dependent cell lines, where IL-3 maintains phosphorylation of the proapoptotic $\mathrm{BH}-3$-only $\mathrm{Bcl}-2$ family molecule $\mathrm{BAD}$ through the PI-3K/Akt pathway. ${ }^{47}$

However, in our cellular model blocking of the PI-3K/Akt pathway was not sufficient to induce apoptosis (unpublished observation). In general, $\mathrm{BH}-3$-only proteins are thought to exert proapoptotic activity by binding to $\mathrm{Bcl}-2$ or its homolog thus neutralizing their anti-apoptotic function. For another member of this Bcl-2 subfamily, Bid, it was shown that the release of a $15 \mathrm{kDa}$ fragment of Bid cleaved by caspase-8 or other caspases could mediate mitochondrial damage ${ }^{48-50}$ The cowpox virus-encoded serpin-like protease inhibitor crmA protects cells from death receptorinduced apoptosis by blocking caspase-activity. However, since it was shown that crmA was not able to block IL-2 deprivation-induced apoptosis in activated $\mathrm{T}$ lymphoblasts in a mouse model, ${ }^{42}$ it is unlikely that a caspasedependent, death receptor-mediated process initiates apoptosis-induction after cytokine withdrawal. In this regard, the recent observation of the proapoptotic activity of the BH3-only protein Bim and the effects seen in Bim knock-out mice could be helpful. ${ }^{51,52}$ Bim activity is regulated by interaction with the LC8 cytoplasmic dynein light chain and several apoptotic stimuli including cytokine withdrawal lead to the translocation of Bim and LC8 from the dynein motor complex to $\mathrm{Bcl}-2$ and to the neutralization of its antiapoptotic activity. This process did not require caspase activation, however, it was found that the multipotent caspase inhibitor ZVAD-FMK inhibited cell death without affecting Bim translocation. ${ }^{53}$ Therefore, it is suggested that this process constitutes an initiating event in apoptosis signaling. This model would also fit to our finding of apoptosis inhibition in our cellular model by zVAD-FMK (Figure 6).

Amongst other intracellular regulators, which are thought to play a key role in executing apoptosis in response to a wide range of different stimuli, the members of the cysteine protease family (the caspases) are the best examined. Until now, at least 11 members of this family with sequence homology to the $C$. elegans gene ced-3 have been identified in human cells. Through adapter molecules, such as FADD (Fas-associated death domain protein) for Fas signals, cell death receptors are directly linked to caspases, which are subsequently activated. However, the precise role of all known caspases in different cell death pathways and various cell types is still poorly understood. For example, in Rat-1 fibroblasts, apoptosis is not completely abrogated by the inhibition of caspases. ${ }^{54}$ Vasilakos et al. ${ }^{55}$ previously reported that ICE-like protease is not involved in IL-2 deprivation-induced cell death in the mouse cell line CTLL-2. In contrast, recent published papers suggest that different protease family members are likely to be critical in different cytokinedependent murine $T$ cell lines. ${ }^{39,56}$ Therefore, we analyzed caspase cleavage activity in our cellular model after cytokine deprivation. We found substrates with different specificities to known caspases to be cleaved when incubated with cytoplasm from lymphoblasts after cytokine withdrawal. However, from previous published studies which tried to define substrate specificities of the caspase family proteases it is known that they have partially overlapping or even identical substrate specificities suggesting redundant effector functions in vivo. ${ }^{40,41}$ As for the above substrates described, WEHD is the shared recognition sequence for caspase-1, -4 and-5. Caspase-3 and -7 identically recognize DEVD and additionally recognize VDVAD-AMC as a substrate which is also cleaved by caspase-2. According to the proposed role for cleavage of lamin A, VEID-AFC seemed to be preferentially cleaved by caspase-6. But also IETD-AMC could be cleaved by caspase- 6 in addition to caspase- 8 and granzyme B.

This cleavage activity was also present in cells from a CSS-patient with a fas gene mutation which further indicates that intracellular pathways mediating apoptosis are not negatively affected by this mutation. Furthermore, 
since we could show increased spontaneous in vitro apoptosis of $\mathrm{CD}^{+}, \mathrm{CD}^{+}$and $\mathrm{CD}^{-} \mathrm{CD}^{-}$(double negative) $T$ cells in the patients with the fas mutation, ${ }^{29}$ our results of enhanced cleavage activities for some of the used caspase substrates in the lysates from one of these patients might argue for compensatory, CD95-independent pathways leading to apoptotic cell death in those patients. To point out the role of specific caspases in our model the expression of caspase-8, caspase- 3 and the expression of PARP as a known substrate of caspase- 3 in activated peripheral human T lymphocytes after IL-2 withdrawal were analyzed. FLICE (caspase-8) is predominantly expressed as two functionally active isoforms, caspase-8/a and caspase-8/b, and stimulation through Fas leads to rapid recruitment and cleavage of both isoforms in the cell lines tested. ${ }^{6}$ We were able to confirm this in Jurkat $\mathrm{T}$ cells and $\mathrm{PHA}$ blasts treated with anti-Fas mAb (Figure 8B). By contrast, in PHA blasts expression but not activation of either isoforms at any time after IL-2 withdrawal could be observed (Figure 8A). Caspase-3 expression could not be observed in human lymphoblasts after activation. In contrast, induction of apoptosis by IL-2 withdrawal is preceded by an upregulation in procaspase-3 expression along with upregulated expression of the p17 subunit of the active complex. These changes were accompanied by degradation of PARP. Thus, our data strongly argue for an involvement of caspase- 3 in the execution of apoptosis in our model, whereas caspase-8 might play a minor role, again highlighting differences between growth factor withdrawal-induced and Fas-mediated apoptosis in human lymphoblasts on the molecular level.

\section{Materials and Methods}

\section{Cell preparation}

Peripheral blood mononuclear cells (PBMC) were isolated from heparinized peripheral blood by Ficoll-Hypaque (BAG, Lich, Germany) density gradient centrifugation, washed twice with PBS, and resuspended in RPMI 1640 (Gibco BRL, Eggenstein, Germany) supplemented with $4 \mathrm{mM}$ L-glutamine, $10 \mathrm{mM}$ HEPES buffer, $100 \mathrm{U} /$ $\mathrm{ml}$ penicillin, $100 \mu \mathrm{g} / \mathrm{ml}$ streptomycin (all BioWitthaker, Verviers, Belgium), and $10 \%(\mathrm{v} / \mathrm{v})$ heat-inactivated fetal calf serum (FCS) (Gibco BRL). For generation of PHA blasts, freshly isolated PBMC were activated with $1 \mu \mathrm{g} / \mathrm{ml}$ phytohemagglutinin (PHA) (Sigma Chemical, Deisenhofen, Germany) and IL-2 (10 U/ml, Boehringer Mannheim, Mannheim, Germany) for 6 days with medium being replenished every 2 days. Thereafter, cells were expanded with $10 \mathrm{U} /$ $\mathrm{ml} \mathrm{IL-2} \mathrm{alone} \mathrm{for} \mathrm{at} \mathrm{least} \mathrm{another} 2$ days. Resulting PHA blasts were extensively washed and cultured as indicated.

\section{Antibodies and reagents}

CD95-mediated apoptosis was induced with anti-Fas IgM (clone $\mathrm{CH}$ 11, Immunotech, Hamburg, Germany). For blocking experiments an antagonistic Fas mAb (clone SM1/23, Bender MedSystems, Vienna, Austria) or a mAb against FasL (clone NOK-1, Pharmingen, San Diego, CA, USA) were used. Anti-PARP mAb was generously provided by $\mathrm{Dr} G$ Poirier (Quebec, Canada). For Western blot experiments anti-FLICE mAb was purchased from Pharmingen and anti-CPP32 mAb from Transduction Laboratories (Lexington, KT, USA). Polyclonal anti-ICE and monoclonal anti-Bcl-2, anti-Bcl- $\mathrm{X}_{\mathrm{L}}$ and
anti-Bax antibodies, the tetrapeptide inhibitors of ICE-like proteases (Ac-DEVD-CHO and Ac-YVAD-CHO), were obtained from Calbiochem (Bad Soden, Germany). The caspase inhibitor Z-Val-Ala-Asp(OMe)fluoromethylketone (zVAD-FMK) and the fluorogenic caspase substrates Ac-VDVAD-AMC, Ac-WEHD-AMC and Ac-IETD-AMC were obtained from Alexis (Grünberg, Germany). The fluoregenic caspase substrates Ac-DEVD-AFC and Ac-VEID-AFC were purchased from Pharmingen.

\section{Quantification of apoptosis}

Microscopic examinations of the cell cultures prone to undergo apoptosis revealed morphological changes like zeiosis. For quantification of apoptosis, DNA staining with propidium iodide (PI) (Sigma Chemical, Deisenhofen, Germany) and flow cytometry analysis were performed as previously described. ${ }^{57}$ In brief, $4 \times 10^{5}$ cells were pelleted with $200 \times \mathrm{g}$ and gently resuspended in $150 \mathrm{ml}$ hypotonic fluorochrome solution of $50 \mathrm{mg} / \mathrm{ml} \mathrm{PI}$ in $0.1 \%$ (w/v) sodium citrate plus $0.1 \%(\mathrm{v} / \mathrm{v})$ Triton X-100 (Sigma Chemical, Deisenhofen, Germany). After a minimum period of $6 \mathrm{~h}$ in the dark at $4^{\circ} \mathrm{C}$, samples were analyzed on a FACScan (Coulter, Hialeah, FL, USA). The percentage of apoptotic cells was calculated as follows: percentage of cells with subdiploid DNA content $\times 100$ divided by percentage of all cells positive for PI-staining.

In some experiments detection of phosphatidylserine exposure on the surface of the cell membrane as an early marker of apoptosis was used as an alternative read-out for apoptosis. Cells were incubated with FITC-conjugated Annexin V following the manufacturer's protocol (Alexis, Grünberg, Germany) and subsequently analyzed by flow cytometry.

\section{Cytofluorometric analysis of mitochondrial transmembrane potential $\left(\Delta \Psi_{\mathrm{m}}\right)$}

To measure $\Delta \Psi_{\mathrm{m}}$ cells were labeled with $100 \mathrm{nM}$ of the cationic lipophilic fluorochrome $3,3^{\prime}$ dihexyloxacarbocyanine iodide $\left(\mathrm{DiOC}_{6}\right)$ (Molecular Probes, Eugene, OR, USA) for $20 \mathrm{~min}$ at $37^{\circ} \mathrm{C}$ and immediately analyzed by flow cytometry for fluorochrome incorporation as described. ${ }^{36}$ In control experiments, cells were stained in the presence of $200 \mu \mathrm{M}$ of the $\Delta \Psi_{\mathrm{m}}$ uncoupling agent carbonyl cyanide mchlorophenyl-hydrazone (mCICCP; Calbiochem, Bad Soden, Germany).

\section{Spectrofluorometric analysis of caspase enzyme activity}

Total protein lysates from $1 \times 10^{7}$ PHA-activated and IL-2-expanded lymphoblasts were prepared at $4{ }^{\circ} \mathrm{C}$ using lysis buffer containing $50 \mathrm{mM}$ Tris $\mathrm{pH} 7.6,150 \mathrm{mM} \mathrm{NaCl}$ and $1 \%(\mathrm{v} / \mathrm{v})$ Triton X-100. Supernatants were clarified by centrifugation for $10 \mathrm{~min}$ at $10000 \times g$ at $4{ }^{\circ} \mathrm{C}$ and protein concentration was determined using a Bradford method protein assay kit. To determine caspase enzyme activity in the cell lysates equal amounts of the total protein preparation were assessed to spectrofluorometric monitored release of fluorochromes from caspase specific substrates in a PTI spectrofluorometer (PTI, Toronto, Canada). The system was equilibrated with $1 \mathrm{ml}$ assay buffer containing $20 \mathrm{mM}$ HEPES, $100 \mathrm{mM} \mathrm{NaCl}, 10 \mathrm{mM}$ DTT, $1 \mathrm{mM}$ EDTA, $0.1 \%$ CHAPS and $10 \%$ sucrose, $\mathrm{pH} 7.2$ and the fluorogenic substrate (final concentration $2 \mu \mathrm{g}$ ) for $5 \mathrm{~min}$ at $37^{\circ} \mathrm{C}$ prior addition of $100 \mu \mathrm{g}$ of the total protein preparation. Release of AMC or AFC was monitored continuously at $37^{\circ} \mathrm{C}$ using an excitation wavelength of $380 \mathrm{~nm}$ and an emission wavelength of $460 \mathrm{~nm}$ for 
AMC and an excitation wavelength of $400 \mathrm{~nm}$ and an emission wavelength of $505 \mathrm{~nm}$ for AFC, respectively.

\section{Western blot analysis of protein expression}

IL-2 expanded PHA blasts were extensively washed and aliquots of $1 \times 10^{7}$ cells were cultured in medium. Cells were lysed after the indicated time in lysis buffer containing $50 \mathrm{mM}$ Tris $\mathrm{pH} 7.6,150 \mathrm{mM}$ $\mathrm{NaCl}, 5 \mathrm{mM}$ EDTA, 0.5\% (v/v) NP-40, 1\% (v/v) Triton X-100, $1 \mathrm{mM}$ sodium vanadate, $1 \mathrm{mM}$ phenylmethane-sulfonyl fluoride (PMSF), $10 \mu \mathrm{g} / \mathrm{ml}$ aprotinin, $10 \mu \mathrm{g} / \mathrm{ml}$ pepstatin and $10 \mu \mathrm{g} / \mathrm{ml}$ leupeptin at $4^{\circ} \mathrm{C}$ for $1 \mathrm{~h}$ (all reagents from Sigma Chemical, Deisenhofen, Germany). Supernatants were clarified by centrifugation for $10 \mathrm{~min}$ at $10000 \times g$ at $4{ }^{\circ} \mathrm{C}$. Protein concentration was determined using a Bradford method protein assay kit (Bio-Rad, Munich, Germany). Twenty $\mu \mathrm{g}$ of total protein lysates from each sample were boiled in $2 \times$ SDS sample buffer for $5 \mathrm{~min}$ and resolved by SDS-PAGE. Immunoblots were performed by semi-dry transfer from the proteins onto nitrocellulose membranes. Unspecific binding sites were blocked in freshly prepared $5 \%$ nonfat dry milk in PBS $/ 0.1 \%$ Tween 20 for at least $30 \mathrm{~min}$ at RT. One $\mu \mathrm{g} / \mathrm{ml}$ of the specific antibody as indicated was incubated in blocking buffer overnight at $4^{\circ} \mathrm{C}$. Subsequently, $1 \mu \mathrm{g} / \mathrm{ml}$ horseradish peroxidaseconjugated goat anti-mouse IgG was added in blocking buffer for $1.5 \mathrm{~h}$ at RT. Detection was performed using enhanced chemiluminescence (ECL, Amersham, Braunschweig, Germany).

\section{Acknowledgements}

We thank Dr Schulze-Koops for critical reading of the manuscript. This work was supported by SFB 263 and BMFT-IZKF grants to H-M Lorenz.

\section{References}

1. Kerr JF, Wyllie AH and Currie AR (1972) Apoptosis: a basic biological phenomenon with wide-ranging implications in tissue kinetics. Br. J. Cancer. 26 239-257

2. Cohen JJ (1991) Programmed cell death in the immune system. Adv. Immunol 50: $55-85$

3. Krammer PH, Behrmann I, Daniel P, Dhein J and Debatin KM (1994) Regulation of apoptosis in the immune system. Curr. Opin. Immunol. 6: 279-289

4. Boise LH, Minn AJ and Thompson CB (1995) Receptors that regulate T-cell susceptibility to apoptotic cell death. Ann. N. Y. Acad. Sci. 766: 70-80

5. Klas C, Debatin KM, Jonker RR and Krammer PH (1993) Activation interferes with the APO-1 pathway in mature human T cells. Int. Immunol. 5: 625-630

6. Scaffidi C, Medema JP, Krammer PH and Peter ME (1997) FLICE is predominantly expressed as two functionally active isoforms, caspase-8/a and caspase-8/b. J. Biol. Chem. 272: 26953-26953

7. Nicholson DW and Thornberry NA (1997) Caspases: killer proteases. Trends Biochem. Sci. 22: 299-306

8. Cohen GM (1997) Caspases: the executioners of apoptosis. Biochem. J.326:1 16

9. Cohen PL and Eisenberg RA (1991) Lpr and gld: single gene models of systemic autoimmunity and lymphoproliferative disease. Annu. Rev. Immunol. 9: 243269

10. Mysler E, Bini P, Drappa J, Ramos P, Friedman SM, Krammer PH and Elkon KB (1994) The apoptosis-1/Fas protein in human systemic lupus erythematosus. J. Clin. Invest. 93: 1029-1034

11. McNally J, Yoo DH, Drappa J, Chu J, Yagita LH, Friedman SM and Elkon KB (1997) Fas ligand expression and function in systemic lupus erythematosus. J. Immunol. 159: 4628-4636

12. Van Parijs L, Ibraghimov $A$ and Abbas AK (1996) The roles of costimulation and Fas in T cell apoptosis and peripheral tolerance. Immunity 4: 321-328
13. Teh SJ, Dutz JP, Motyka B and Teh HS (1996) Fas (CD95)-independent regulation of immune responses by antigen- specific CD4-CD8+ T cells. Int. Immunol. 8: 675-681

14. Zimmermann C, Rawiel M, Blaser C, Kaufmann M and Pircher H (1996) Homeostatic regulation of CD8+T cells after antigen challenge in the absence of Fas (CD95). Eur. J. Immunol. 26: 2903-2910

15. Strasser A, Harris AW, Huang DC, KrammerPHand Cory S(1995)Bcl-2 andFas/ APO-1 regulate distinct pathways to lymphocyte apoptosis. EMBO J. 14:61366147

16. Lenardo MJ (1991) Interleukin-2 programs mouse alpha beta T lymphocytes for apoptosis. Nature 353: $858-861$

17. Wang R, Rogers AM, Rush BJ and Russell JH (1996) Induction of sensitivity to activation-induced death in primary CD4+ cells: a role for interleukin-2 in the negative regulation of responses by mature CD4+ T cells. Eur. J. Immunol. 26: 2263-2270

18. Fournel S, Genestier L, Robinet E, Flacher M and Revillard JP (1996) Human T cells require IL-2 but not $\mathrm{G} 1 / \mathrm{S}$ transition to acquire susceptibility to Fas-mediated apoptosis. J. Immunol. 157: 4309-4315

19. Kneitz B, Herrmann T, Yonehara S and Schimpl A (1995) Normal clonal expansion but impaired Fas-mediated cell death and anergy induction in interleukin-2-deficient mice. Eur. J. Immunol. 25: 2572-2577

20. Suzuki H, Kundig TM, Furlonger C, Wakeham A, Timms E, Matsuyama T, Schmits R, Simard JJ, Ohashi PS, Griesser H, Taniguchi T, Paige CJ and Mak TW (1995) Deregulated T cell activation and autoimmunity in mice lacking interleukin-2 receptor beta. Science 268: 1472-1476

21. Van Parijs L, Biuckians A, Ibragimov A, Alt FW, Willerford DM and Abbas AK (1997) Functional responses and apoptosis of CD25 (IL-2R alpha)-deficient T cells expressing a transgenic antigen receptor. J. Immunol. 158: 3738-3745

22. Armant M, Delespesse G and Sarfati M (1995) IL-2 and IL-7 but not IL-12 protect natural killer cells from death by apoptosis and up-regulate bcl-2 expression. Immunology 85: $331-337$

23. Nieto MA, Gonzalez A, Lopez-Rivas A, Diaz-Espada F and Gambon F (1990) IL2 protects against anti-CD3-induced cell death in human medullary thymocytes. J. Immunol. 145: 1364-1368

24. Pericle F, Liu JH, Diaz JI, Blanchard DK, Wei S, Forni G and Djeu JY (1994) Interleukin-2 prevention of apoptosis in human neutrophils. Eur. J. Immunol. 24: 440-444

25. Mor F and Cohen IR (1996) IL-2 rescues antigen-specific T cells from radiation or dexamethasone-induced apoptosis. Correlation with induction of $\mathrm{Bcl}-2$. J. Immunol. 156: 515-522

26. Zubiaga AM, Munoz E and Huber BT (1992) IL-4 and IL-2 selectively rescue Th cell subsets from glucocorticoid- induced apoptosis. J. Immunol. 149: 107-112

27. Lenardo $M$, Chan F, Hornung $F$, McFarland $H$, Siegel $R$, Wang $J$ and Zheng $L$ (1999) Mature T lymphocyte apoptosis - Immune regulation in a dynamic an unpredictable antigenic environment. Annu. Rev. Immunol. 17: 221-253

28. Lorenz H-M, Hieronymus T, Grunke M, Manger B and Kalden JR (1997) Differential role for IL-2 and IL-15 in the inhibition of apoptosis in short-term activated human lymphocytes. Scand. J. Immunol. 45: 660-669

29. Haas JP, Grunke M, Frank C, Kolowos W, Dirnecker D, Leipold G, Hieronymus T, Lorenz H-M and Herrmann M (1998) Increased spontaneous in vitro apoptosis in double negative T cells of humans with a fas/apo-1 mutation. Cell Death Differ. 5: $751-757$

30. Wesselborg S, Engels ICH, Rossmann E, Los M and Schulze-Osthoff K (1999) Anticancer drugs induce Caspase-8/FLICE activation and apoptosis in the absence of CD95 receptor/ligand interaction. Blood 93: 3053-3063

31. Akbar AN, BorthwickNJ, Wickremasinghe RG, Panayoitidis P, Pilling D, Bofill M, Krajewski S, Reed JC and Salmon M (1996) Interleukin-2 receptor common gamma-chain signaling cytokines regulate activated $T$ cell apoptosis in response to growth factor withdrawal: selective induction of anti-apoptotic (bcl-2, bcl-xL) but not pro- apoptotic (bax, bcl-xS) gene expression. Eur. J. Immunol. 26: 294 299

32. Gomez J, Gonzalez A, Martinez AC and Rebollo A (1998) IL-2-induced cellular events. Crit. Rev. Immunol. 18: 185-220

33. Boise LH, Gonzales-Garcia M, Postema CE, Ding L, Lindsten T, Turka LA, Mao X, Nunez G and Thompson CB (1993) bcl-x, a bcl-2-related gene that functions as a dominant regulator of apoptotic cell death. Cell 74: 597-608

34. Strasser A, Harris AW and Cory S (1991) bcl-2 transgene inhibits T cell death and perturbs thymic self-censorship. Cell 67: 889-899 
35. Yang E and Korsmeyer SJ (1996) Molecular thanatopsis: a discourse on the BCL2 family and cell death. Blood 88: 386-401

36. Zamzami N, Marchetti P, Castedo M, Zanin C, Vayssiere JL, Petit PX and Kroemer G (1995) Reduction in mitochondrial potential constitutes an early irreversible step of programmed lymphocyte death in vivo. J. Exp. Med. 181: $1661-1672$

37. Broome HE, Dargan CM, Krajewski S and Reed JC (1995) Expression of Bcl-2, Bcl-x, and Baxafter T cell activation and IL-2 withdrawal. J. Immunol. 155:2311 2317

38. Sarin A, Wu ML and Henkart PA (1996) Different interleukin-1b converting enzyme (ICE) family protease requirements for the apoptotic death of $T$ lymphocytes triggered by diverse stimuli. J. Exp. Med. 184: 2445-2450

39. Ohta T, Kinoshita T, Naito M, Nozaki T, Masutani M, Tsuruo T and Miyajima A (1997) Requirement of the caspase-3/CPP32 protease cascade for apoptotic death following cytokine deprivation in hematopoietic cells. J. Biol. Chem. 272: $23111-23116$

40. Talanian RV, Quinlan C, Trautz S, Hackett MC, Mankovich JA, Banach D, Ghayur T, Brady KD and Wong WW (1997) Substrate specificities of caspase family proteases. J. Biol. Chem. 272: 9677-968

41. Thornberry NA, Rano TA, Peterson EP, Rasper DM, Timkey T, Garcia-Calvo M, Houtzager VM, Nordstrom PA, Roy S, Vaillancourt JP, Chapman KT and Nicholson DW (1997) A combinatoral approach defines specificities of members of the caspase family and granzyme B. J. Biol. Chem. 272: 17907-17911

42. Smith KG, Strasser A and Vaux DL (1996) CrmA expression in T lymphocytes of transgenic mice inhibits CD95 (Fas/APO-1)-transduced apoptosis, but does not cause lymphadenopathy or autoimmune disease. EMBO J. 15: 5167-517

43. Newton K, Harris AW, Bath ML, Smith KGC and Strasser A (1998) A dominant interfering mutant of FADD/MORT1 enhances deletion of autoreactive thymocytes and inhibits proliferation of mature T lymphocytes. EMBO J. 17: $706-771$

44. Zhang J, Cado D, Chen A, Kabra NH and Winoto A (1998) Fas-mediated apoptosis and activation-induced T-cell proliferation are defective in mice lacking FADD/Mort1. Nature 392: 296-300

45. Yang J, LiuX, BhallaK, Kim CN, Ibrado AM, Cai J, Peng TI, Jones DP andWangX (1997) Prevention of apoptosis by Bcl-2: release of cytochrome $\mathrm{C}$ from mitochondria blocked. Science 275: 1129-1132

46. Susin SA, Zamzami N, Castedo M, Hirsch T, Marchetti P, Macho A, Daugas E, Geuskens M and Kroemer G (1996) Bcl-2 inhibits the mitochondrial release of an apoptogenic protease. J. Exp. Med. 184: 1331-1341
47. DelPeso L, Gonzales-Garcia M, Page C, Herrera R and Nunez G (1997) Interleukin-3-induced phosphorylation of BAD through the protein kinase Akt. Science 278: 687-689

48. $\mathrm{LiH}, \mathrm{ZhuH}, \mathrm{Xu}$ CJ and Yuan J (1998) Cleavage of BID by caspase 8 mediates the mitochondrial damage in the Fas pathway of apoptosis. Cell 94: 481-490

49. Luo X, Budihardjo I, Zou H, Slaughter C and Wang X (1998) Bid, a Bc12 interacting protein, mediates cytochrome $c$ release from mitochondria in response to activation of cell surface death receptors. Cell 94: 491-501

50. Han Z, Bhalla K, Pantazis P, Hendrickson EA and Wyche JH (1999) Cif (Cytochrome cefflux-inducing factor) activity is regulated by bcl-2 and caspases and correlates with the activation of Bid. Mol. Cell. Biol. 19: 1381-1389

51. O'Connor L, Strasser A, O'Reilly LA, Hausmann G, Adams JM, Cory S and Huang DC (1998) Bim: a novel member of the Bcl-2 family that promotes apoptosis. EMBO J. 17: $384-395$

52. Bouillet $P$, Metcalf D, Huang DC, Tarlinton DM, Kay TW, Kontgen F, Adams JM and Strasser A (1999) Proapoptotic Bcl-2 relative Bim required for certain apoptotic responses, leukocyte homeostasis, and to preclude autoimmunity. Science 286: $1735-1738$

53. Puthalakath H, Huang DC, O'Reilly LA, King SM and Strasser A (1999) The proapoptotic activity of the $\mathrm{Bcl}-2$ family member $\mathrm{Bim}$ is regulated by interaction with the dynein motor complex. Mol. Cell 3: 287-296

54. McCarthy NJ, Whyte MK, Gilbert CS and Evan GI (1997) Inhibition of Ced-3/ICErelated proteases does not prevent cell death induced by oncogenes, DNA damage, or the Bcl-2 homologue Bak. J. Cell. Biol. 136: 215-227

55. Vasilakos JP, Ghayur T, Carroll RT, Giegel DA, Saunders JM, Quintal L, Keane KM and Shivers BD (1995) IL-1 beta converting enzyme (ICE) is not required for apoptosis induced by lymphokine deprivation in an IL-2-dependent T cell line. J. Immunol. 155: 3433-3442

56. Fujita N, Nagahashi A, Nagashima K, Rokudai S and Tsuruo T (1998) Acceleration of apoptotic cell death after the cleavage of $\mathrm{Bcl}-\mathrm{XL}$ protein by caspase-3-like proteases. Oncogene 17: 1295-12304

57. Nicoletti I, Migliorati G, Pagliacci MC, Grignani F and Riccardi C (1991) A rapid and simple method for measuring thymocyte apoptosis by propidium iodide staining and flow cytometry. J. Immunol. Methods 139: 271-279 